\title{
Reduced gene expression of UCP2 but not UCP3 in skeletal muscle of human obese subjects
}

\author{
L. Nordfors ${ }^{1}$, J.Hoffstedt ${ }^{2}$, B. Nyberg ${ }^{3}$, A. Thörne ${ }^{3}$, P. Arner ${ }^{2}$, M. Schalling, ${ }^{1}$ F. Lönnqvist ${ }^{2}$ \\ ${ }^{1}$ Karolinska Institute, Neurogenetics Unit, Department of Molecular Medicine, Karolinska Hospital, Stockholm, Sweden \\ ${ }^{2}$ Karolinska Institute, Department of Medicine and Research Center, Huddinge University Hospital, Stockholm, Sweden \\ ${ }^{3}$ Karolinska Institute, Department of Surgery, Huddinge University Hospital, Stockholm, Sweden.
}

\begin{abstract}
Summary Massive overweight is an increasing health problem and underlies several complications which in turn result in premature death. The mechanisms underlying the imbalance between energy intake and energy expenditure, that lead to obesity in humans, are still only partly understood. In rodents, heat generation and the burning of calories by the mitochondrial uncoupling protein 1 (UCP1) are important for metabolic control. However, UCP1 is exclusively expressed in brown fat which is only present in limited amounts in human adults. The recent characterization of two new uncoupling proteins, UCP2 and UCP3, may elucidate potentially important pathways for energy expenditure regulation in man. The aim of this study was to investigate whether obesity is accompanied by aberrations in UCP2 and UCP3 regulation. Expression of these two genes was exam-
\end{abstract}

ined using in situ hybridization in six lean and six obese, but otherwise healthy, men. The UCP2 expression was decreased by $28 \%(p=0.001)$ in the abdominal muscle of the obese subjects. No differences in UCP3 expression were observed between obese and control subjects, although there was great variation in the expression between subjects. In conclusion, these data suggest an impaired activity of the mitochondrial uncoupling protein UCP2, but probably not UCP3, in obese subjects. This may result in decreased energy expenditure and contribute to the development and maintenance of obesity. [Diabetologia (1998) 41: 935-939]

Keywords Energy expenditure, fuel oxidation, in situ hybridization, thermoregulation, mRNA
Obesity has become a major health problem in most western societies [1]. Although the mechanisms behind the regulation of energy intake and energy expenditure are still unclear, recent findings have contributed to a better understanding of body weight regulation. Body weight and fat distribution are determined by both environmental and genetic factors, but with the advance of obesity research, the impact of the latter has become emphasized [2, $3,4]$.

Received: 5 December 1997 and in revised form: 18 February 1998

Corresponding author: F. Lönnqvist, M.D., Department of Medicine, Huddinge University Hospital, S-14186 Huddinge, Sweden

Abbreviations: UCP, Uncoupling protein.
In rodents, activation of the sympathetic nervous system leads to uncoupling protein (UCP)1-mediated heat production in brown adipose tissue [5]. Brown adipose tissue is the physiological opposite of white adipose tissue, designed to burn, not store, energy. This energy is released as heat by the uncoupling of fuel oxidation from the conversion of ADP to ATP. Until recently, uncoupled respiration was thought to occur exclusively in the mitochondria of brown adipocytes [6, 7]. Humans, unlike rodents, have very little brown adipose tissue and this pathway has been considered to be insignificant to energy consumption in man. Recently, two novel uncoupling proteins, (UCP2) [8] and (UCP3) [9], were reported. UCP2, which has $59 \%$ amino acid identity to UCP1 and shares many features with UCP1, has been shown to influence mitochondrial activity, to partially uncouple respiration in yeast, and it is up-regulated in the 
white fat of mice in response to a fat-rich diet [8]. Moreover UCP2 is expressed at relatively high levels in a number of human tissues other than brown fat, including tissues rich in macrophages. It has been suggested that $\mathrm{UCP} 2$ might play a role in immunity as well as in thermoregulatory responses to infection [8]. UCP3 is $57 \%$ homologous with UCP1 and $73 \%$ homologous with UCP2, and is highly skeletal muscle-specific [9]. Both UCP2 and UCP3 are expressed at higher levels than UCP1 in man. This implies that, in humans, the uncoupling of fuel oxidation through UCP2 and/or UCP3 might play a more important role in energy expenditure than UCP1.

In the present study the expression of $\mathrm{UCP} 2$ and UCP3 in abdominal skeletal muscle was investigated in lean and massively obese men using in situ hybridization histochemistry.

\section{Subjects and methods}

Subjects. The study comprised six markedly obese, otherwise healthy, drug-free subjects. Body mass index (BMI), defined as body weight divided by height in squares, was $39 \pm 3 \mathrm{~kg} / \mathrm{m}^{2}$ (means \pm SEM), with a range 35.3 to $42.6 \mathrm{~kg} / \mathrm{m}^{2}$. The subjects underwent surgical weight reduction treatment through gastric banding. A control group consisted of six never-obese subjects (BMI $24 \pm 2 \mathrm{~kg} / \mathrm{m}^{2}$, range $21.0-26.6 \mathrm{~kg} / \mathrm{m}^{2}$ ) who were undergoing elective inguinal hernia surgery (but otherwise healthy) at Huddinge University Hospital. All subjects were Caucasian. The two groups were matched for sex and age. The ages of the subjects ranged from 26 to 70 years. The average age was 39 years (range 26 to 52 years) in the obese group and 50 years (range 28 to 70 years) in the non-obese group. All obese men had a waist-to-hip ratio greater than 1.00 , which indicates that they had an upper-body fat distribution. Waist circumference was measured around umbilicus and hip circumference around spina iliaca anterior superior.

The subjects fasted overnight. No particular dietary restrictions were imposed prior to fasting. General anaesthesia was induced at 08.00 hours by a short-acting barbiturate and maintained by fentanyl and a mixture of oxygen and nitrous oxide. Intravenous $\mathrm{NaCl} 154 \mathrm{mmol} / \mathrm{l}$ (saline) was administered prior to the muscle biopsies, which were taken from the rectus anterior skeletal muscle at the beginning of the surgical procedure. The study was approved by the ethics committee of Karolinska Institute, Stockholm, and all the patients gave informed consent to participate in the study.

The muscle tissue specimens ranged from $200 \mathrm{mg}$ to $1000 \mathrm{mg}$ and were immediately frozen unfixed on dry ice at the operation theater and then stored at $-70^{\circ} \mathrm{C}$ until sectioned.

Preparation of gene probes. A 45-mer oligonucleotide, complementary to nucleotides 519-563 of the human UCP2 gene, and a sense 45-mer oligonucleotide for the same region, as well as a 45-mer oligonucleotide, complementary to nucleotides 135-179 of the human UCP3 gene, detecting both the long and the short form, were synthesized and purified by MedProbe, St. Hanshaugen, Oslo, Norway. To exclude the possibility of any cross-hybridization of UCP family members or other human mRNAs, homology searches were carried out. The homology between the UCP2 probe and UCP3 mRNA is $69 \%$, well below $92 \%$ which is the lower limit for hybridization in the current protocol. A search in Genome Data Base showed no clones of significant homology, except for the intended targets. A 48-mer gamma-actin oligonucleotide probe, complementary to nucleotides 325-372 [10], was obtained from Pharmacia Biotech, Uppsala, Sweden, and was used to ensure, first that the mRNA was of equally good quality in all examined tissue samples and second that changes in UCP2 mRNA were specific for the latter gene. The oligonucleotides were subsequently labelled with a ${ }^{35}$ S-labelled dATP at the 3 ' end using terminal dideoxy nucleotidyl transferase to a specific activity of $2 \times 10^{9} \mathrm{cpm} / \mu \mathrm{g}$ and purified in a Nensorb 20 column.

In situ hybridization. The tissue was cut at $14 \mu \mathrm{m}$ thickness in a cryostat, thawed onto Fisher probe on + slides (Fisher Biotech, Springfield, N.J.), and processed for in situ hybridization [11]. Sections were incubated at $42^{\circ} \mathrm{C}$ for $15-18 \mathrm{~h}$ with $10^{6} \mathrm{cpm}$ of labelled probe per $100 \mu \mathrm{l}$ of a solution containing $50 \%$ formamide, $4 \times \mathrm{SSC}, 1 \times$ Denhardt's solution, $1 \%$ sarcosyl, 0.02 mol sodiumphosphate $\left(\mathrm{NaPO}_{4}, \mathrm{pH} 7.0\right)$ and $10 \%$ dextran sulphate mixed with $500 \mu \mathrm{g} / \mathrm{ml}$ sonicated salmon sperm DNA and $200 \mathrm{mmol} / \mathrm{l}$ dithiothreitol. Sections were rinsed in $1 \times \mathrm{SSC}$ at $55^{\circ} \mathrm{C}$ for $1 \mathrm{~h}$, dried and exposed to Amersham Hyperfilm $\beta$ max X-ray film for 14 days. Some sections were dipped in NTB 2 nuclear track emulsion (Kodak), followed by an 8 week long exposure, developed in Kodak D19 for 3 min, fixed in Kodak 3000A and analysed in a Zeiss dark field microscope. Pictures from these emulsion radiographs were taken using T-max 100 film. Slides that were not dipped in NTB 2 nuclear track emulsion were stained by treatment with haematoxylin and eosin.

Quantification of in situ hybridization autoradiographs. Muscle biopsy sections from all six obese and six non-obese subjects were mounted on the same glass to simplify the comparison between the groups and between different individuals. Slides were processed together as a single batch through hybridization, washes, autoradiographic exposure and computerized image analysis. Any batch effect possible would therefore already occur at the stage of sectioning. We controlled for this possible variability by calculating the average intensity from three sections from each individual tissue in the final analysis. To control for possible variations in the image analysis process, several independent measurements were made. Autoradiographic ${ }^{14} \mathrm{C}$ microscale strips (Amersham International, Little Chalfont, UK) ranging from 31 to $883 \mathrm{nCi} / \mathrm{g}$ were coexposed with the tissue sections standards to linearize the film response to radiation. The results from the different measurements were highly reproducible. Quantification was performed on a Macintosh IIx (Apple Computer Inc, Cupertino, Calif., USA) equipped with a Quick Capture frame grabber board (Data Translation, Marlboro, Mass., USA), a Northern Light precision illuminator (Imaging Research, St. Catherines, Ontario, Canada) and a Hamamatsu CCD (Hamamatsu, Hamamatsu City, Japan) camera equipped with a Nikon $55 \mathrm{~mm}$ lens. To process the images, Image (NIMH, Bethesda, Md., USA) software was used. Each frame was digitized to a $512 \times 512$ matrix with 256 grey levels for each picture element. The greylevels corresponding to the 5 standards lying within the exposure range of the film were determined and used in a third degree polynomial approximation to construct a greylevel to activity transfer function.

Statistical analysis. Values are given as the means \pm SEM. The Student's two-tailed unpaired $t$-test and the chi-square test were employed for statistical comparisons. All statistical calculations were performed with Microsoft Excel, 5.0.

Drugs and chemicals. Formamide was from Baker Chemicals B W, Deventer, Holland. Salmon sperm DNA, sodium cacodylate, Tris base, cobolt chloride, sodium chloride, sodium cit- 
Table 1. Data in six obese and six nonobese men

\begin{tabular}{lccl}
\hline & Obese & Nonobese & P \\
\hline Age & $39.5 \pm 10.6$ & $50.6 \pm 18.2$ & NS \\
BMI, kg/m ${ }^{2}$ & $39.2 \pm 2.7$ & $24.0 \pm 2.1$ & - \\
$\mathrm{UCP} 2, \mathrm{nCi} / \mathrm{g}$ & $67.5 \pm 6.4$ & $93.8 \pm 12.6$ & 0.001 \\
$\mathrm{UCP} 3, \mathrm{nCi} / \mathrm{g}$ & $261.42 \pm 32.1$ & $256.5 \pm 40.9$ & $\mathrm{NS}$ \\
Gamma-actin, nCi/g & $6169.1 \pm 644.5$ & $4270.8 \pm 581.0$ & 0.0003 \\
\hline
\end{tabular}

The values are means \pm SEM. The groups were compared using the Student's $t$-test. NS = not significant

rate, bovine serum albumin, Ficoll, polyvinylpyrrolidone and sarcosyl (N-laurylsarcosine) were from Sigma, St Louis, Mo., USA. Sodiumphosphate ( $\mathrm{pH} 7.0$ ), dextran sulphate and dithiotreitol were from Pharmacia, Uppsala, Sweden. Terminal deoxynucleotidyl transferase was from Amersham International, Amersham, UK. ${ }^{35}$ S-labelled dATP NEG034H and Nensorb columns were from NEN, Du Medical, Rochester, USA.

\section{Results}

UCP2, UCP3, and gamma-actin gene expression were measured in skeletal muscle from six obese, but otherwise healthy, and six non-obese male control subjects. Gamma-actin was used as a positive control for the presence of mRNA and to ensure the quality of the tissues examined (Table 1).

Figure 1 shows a dark field emulsion autoradiograph of the UCP2 expression in skeletal muscle tissue from one non-obese individual (A), one markedly obese individual (B), and the obese individual hybridized with a sense oligonucleotide (C). Distinct UCP2 mRNA labelling was seen in both the massively obese and the non-obese subject. However, in the obese subject the silver grain density was visibly lower than in the non-obese subject. The background was generally insignificant, with absolute values close to zero, compared with individual UCP2 density values ranging from 55 to $110 \mathrm{nCi} / \mathrm{g}$. Image analysis statistics of triplicate skeletal muscle sections were obtained from the obese and the non-obese men. Using computerized image analysis of high resolution $\mathrm{X}$ ray films, mRNA levels, expressed in $\mathrm{nCi} / \mathrm{g}$, were determined for each tissue section. The distribution of the individual mean UCP2 and UCP3 values (Fig. 2) displayed considerable variability in gene expression between individuals. However, as depicted in Figure $2 \mathrm{~A}$, the UCP2 values in the two groups were clearly distinct with a $28 \%$ lower UCP2 expression in the skeletal muscle biopsies from obese subjects as compared with non-obese subjects $(p<0.001)$. Using the chi-square test, three out of six obese subjects demonstrated an expression that was more than 2 standard deviations below the mean value in the non-obese group. None of the subjects in the non-obese group $(n=6)$ scored outside 1 standard deviation from the mean. However, no difference in UCP3 expression
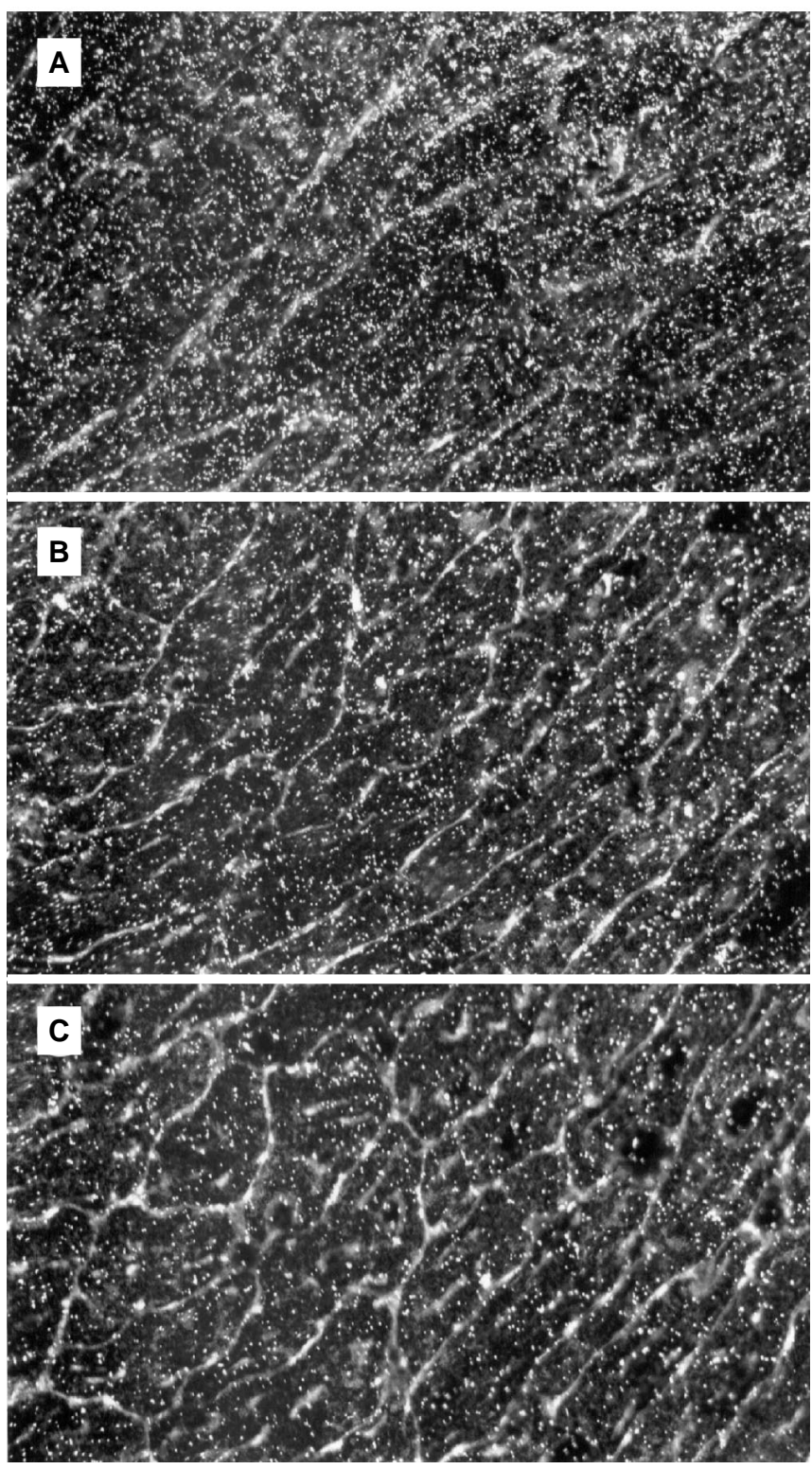

Fig.1A-C. Dark-field emulsion autoradiograph of UCP2 mRNA in skeletal muscle of a non-obese (A) and an obese (B) male subject, and the obese subject hybridized with a sense oligo nucleotide probe $(\mathbf{C})$. Note the even distribution of grains over all muscle fibres, which are here seen as mostly longitudinally sectioned structures covering the entire photo micrographs. The grain density is lower in the obese than in the non-obese subject

was observed in parallel experiments on the same subjects (Fig. 2B).

A routine quality control histological examination was performed. Two of the samples, one obese and one control, contained either an excess of fat ( $>10 \%$ ), or artefacts introduced during the sectioning procedure. The remaining tissue sections were of high quality with considerably more than $90 \%$ of the surface represented by muscle tissue. The difference in UCP2 expression was still $28 \%$ with these two samples excluded, now with an even higher signifi- 

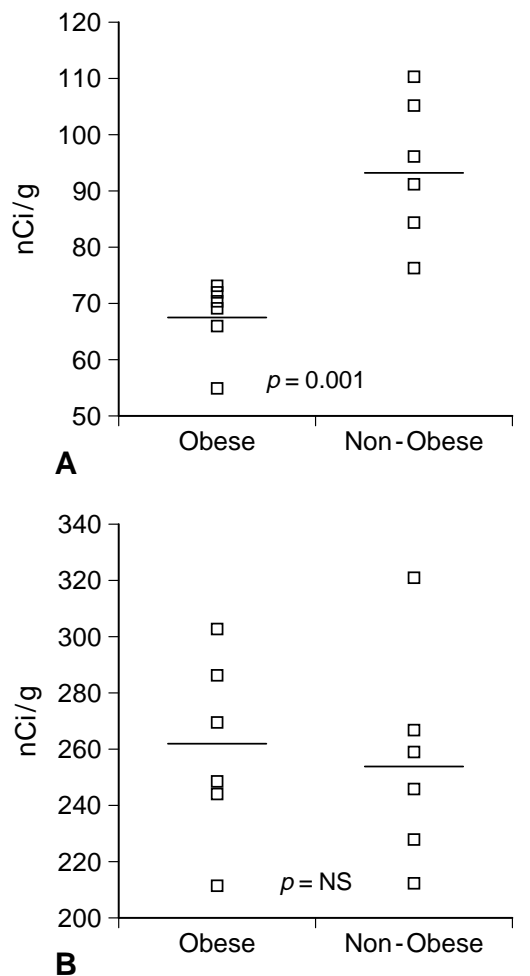

Fig. 2. A Skeletal muscle grain density values, reflecting the individual UCP2 gene expression in obese and non-obese subjects. Each in situ hybridization was performed on six obese and six non-obese subjects in parallel. B Skeletal muscle grain density values, reflecting the individual UCP3 gene expression in the same subjects as in $\mathbf{A}$. All values are given as individual mean values. Standard errors of mean values were omitted for the clarity of the figure, but were generally about 10-20\%

cance $(p<0.0004)$, while UCP3 results remained unchanged.

Image analysis of gamma-actin in muscle tissue showed a difference in the expression between obese and non-obese subjects. Gamma-actin expression in adipose tissue has previously been reported to be slightly higher in obese subjects [12]. In this case the expression ratio was $31 \%$ higher in the obese group as compared with the non-obese group $(p=0.0003)$ with individual grain density values ranging between 3391 and $7025 \mathrm{nCi} / \mathrm{g}$.

\section{Discussion}

The mechanisms underlying the development of obesity are only partly known. However, it is known that obesity results from an intricate network of additive and interactive causes that may be related to DNA sequence variation but also behavioural and life-style characteristics [2]. Furthermore, obesity is a heterogeneous phenotype with several types of distribution of excess fat [13]. Each of these phenotypes may be modulated by a different set of causal factors.
The leptin system clearly has a role in the regulation of energy balance. The characterization of the obese $(o b)$ gene and its product leptin has contributed to an understanding of such a pathway and its potential role in obesity in man [14]. However, energy expenditure regulation, and the potential link between leptin and thermogenic activity, is still largely not known. In rodents, it is believed that leptin may activate the sympathetic nervous system centrally, and lead to the stimulation of heat production in brown adipose tissue via activation of UCP1. Although white and brown adipocytes share several characteristics (i.e. the ability to synthesize and store triglycerides and to release non-esterified fatty acids), they have been considered physiological opposites. While white adipose tissue stores energy, brown adipose tissue dissipates energy and produces heat upon environmental cold exposure, through stimulation by additional non-esterified fatty acids, or due to sympathetic nerve terminal norepinephrine stimulation via $\beta 3$-adrenoreceptors. In mice, deficiency of brown adipose tissue results in hyperphagia and obesity, thereby indicating a crucial role of uncoupling protein (UCP1) for food intake and energy expenditure.

Although their function is still not known, UCP2 and the recently described UCP3 may have a similar role in man. UCP2 maps to several independentlyderived quantitative trait loci associated with obesity on mouse chromosome 7. Furthermore, in white adipose tissue of $\mathrm{A} / \mathrm{J}$ and $\mathrm{B} 6$ mice the expression of UCP2 was up-regulated in response to a high fat diet, which suggests that UCP2 may play a role in metabolic control. However, UCP2 expression did not increase due to cold exposure or $\beta 3$-adrenergic stimulation in white adipose tissue of Swiss mice. This clearly implies that UCP2 is regulated differently from UCP1 [8]. It can not be excluded that UCP2 may be part of the adipose tissue brain feedback control mechanisms regulating energy expenditure. Support for this hypothesis comes from the observations that leptin, which has pronounced effects on the level of sympathoadrenal activity, has been shown to increase UCP2 mRNA levels in white adipocytes when overexpressed in rats [15]. Environmental cold increases UCP2 mRNA levels in rat brown adipose tissue, heart and soleus muscle, which agrees with a putative uncoupling, thermoregulatory, role for the UCP2 protein. However, fasting markedly up-regulates UCP2 expression in skeletal muscle, (but not in brown adipose tissue or heart), which contradicts an uncoupling role in thermogenesis [16].

The reduction of UCP2 mRNA is compatible with a decreased capacity to expend energy in obese subjects. We cannot deduce from the present data whether the $28 \%$ lower UCP2 gene expression in the obese group is due to a lower transcription rate or to a more rapid mRNA turnover. The decrease in $\mathrm{UCP} 2 \mathrm{mR}$ - 
NA may be due to hereditary factors and may also be the consequence of events or situations associated with obesity such as, increased muscle strain or different exercise patterns. Moreover, the technique used in this study measures mRNA levels per tissue area. A different tissue composition in muscle from obese patients could therefore influence measurements. For example, higher skeletal muscle fat content, or larger muscle fibres [17], could lead to the registration of lower values. We controlled for differences in fat content by routine staining and exclusion of any sample with a high muscle fat content. It is unlikely that UCP 2 mRNA levels are reduced as a direct consequence of increased food intake as this, at least in rodents, leads to increased UCP2 mRNA levels [8]. There is no evidence to suggest major differences in resting energy expenditure between lean and obese subjects. However, meta-analysis of eleven studies showed that the resting energy expenditure is significantly lower in post-obese subjects compared to normal weight subjects [18], and it is reasonable to believe that even minor differences in energy expenditure could result in marked changes in BMI over time. Although it is not yet proven that the level of UCP 2 mRNA expression predicts the amount of protein, the reduced expression of the human UCP2 gene in obesity opens the possibility of important mutations in this gene and/or in the gene coding for its regulatory proteins. If this is the case, the characterization of such mutations will lead to a new understanding of obesity and an indication of novel routes towards a pharmacological treatment of obesity.

Acknowledgements. This study was supported by grants from the Swedish Medical Research Council (B94-13XB-10909, B94-13XA 10995, B91-19F-9390-01), Commission of the European Communities (Biomed 2), Karolinska Institute, the Swedish Society of Medicine, the Swedish Diabetes Association and the Foundations of Åke Wiberg, Novo-Nordisk Insulin and Söderberg. Martin Schalling is the recipient of a NARSAD Established Investigator Award.

The excellent technical assistance of Mia Nilsson, Neurogenetics Unit, Karolinska Institute and Britt-Marie Leijonhufvud, Catharina Sjöberg, Huddinge University Hospital was greatly appreciated.

\section{References}

1. Björntorp P (1991) Metabolic implications of body fat distribution. Diabetes Care 14: 1132-1143

2. Bouchard C, Pérusse L (1993) Genetics of obesity. Annu Rev Nutr 13: 337-354
3. Bodurtha JN, Mosteller M, Hewitt JK et al. (1990) Genetic analysis of anthropometric measures in 11-year-old twins: the Medical College of Virginia Twin Study. Pediatr Res 28: $1-4$

4. Stunkard AJ, Foch TT, Hrubec Z (1986) A twin study of human obesity. JAMA 256: 51-54

5. Himms-Hagen J (1990) Brown adipose tissue thermogenesis: interdisciplinary studies. FASEB J 4: 2890-2898

6. Nicholls DG, Locke RM (1984) Thermogenic mechanisms in brown fat. Physiol Rev 64: 1-64

7. Dessolin S, Schalling M, Champigny O et al. (1997) Leptin gene is expressed in rat brown adipose tissue at birth. FASEB J 11: 382-387

8. Fleury C, Neverova M, Collins SH et al. (1997) Uncoupling protein-2: a novel gene linked to obesity and hyperinsulinemia. Nature Genetics 15: 269-272

9. Boss O, Samec S, Paolino-Giacobino A et al. (1997) Uncoupling protein-3: a new member of the mitochondrial carrier family with tissue-specific expression. FEBS Lett 408: $39-42$

10. Erba HP, Gunnig P, Kedes L (1986) Nucleotide sequence of the human gamma cytoskeletal actin mRNA: anomalous evolution of vertebrate non-muscle actin genes. Nucleic Acids Res 14: 5275-94

11. Schalling M, Franco-Cereceda A, Hemsén A et al. (1991) Neuropeptide Y and catecholamine synthesizing enzymes and their mRNAs in rat sympathetic neurons and adrenal glands: studies on expression, synthesis and axonal transport after pharmacological and experimental manipulations using hybridization techiques and radioimmunoassay. Neuroscience 41: 753-766

12. Lonnqvist F, Arner P, Nordfors L, Schalling M (1995) Overexpression of the obese $(o b)$ gene in adipose tissue of human obese subjects. Nat Med 1:950-953

13. Kissebah AH, Vydelingum N, Murray R et al. (1982) Relation of body fat distribution to metabolic complications of obesity. J Clin Endocrinol Metab 54: 254-260

14. Lönnqvist F, Schalling M (1997) Role of leptin and its receptor in human obesity current opinion in Endocrinology and Diabetes 4: 164-171

15. Zhou Y-T, Shimabukuro M, Koyama K et al. (1997) Induction by leptin of uncoupling protein-2 and enzymes of fatty acid oxidation. Proc Natl Acad Sci 94: 6386-6390

16. Boss O, Samec S, Dullo A, Seydoux J, Muzzin P, Giacobino JP (1997) Tissue-dependent upregulation of rat uncoupling protein-2 expression in response to fasting and cold. FEBS Lett 412: 111-114

17. Simoneau J-A, Kelley DE (1997) Skeletal muscle and obesity. In: Bray GA, Bouchard C, James WPT (eds) Handbook of obesity, Marcel Dekker Inc. New York, Basel, Hong Kong, pp 539-553

18. Astrup A, Buemann B, Toubro S, Ranneries C, Raben A (1996) Low resting metabolic rate in subjects predisposed to obesity: a role for thyroid status. Am J Clin Nutr 63: 879-883 